\title{
Guidelines for the Management of Postoperative Pain after Total Knee Arthroplasty
}

\author{
Korean Knee Society \\ Korean Knee Society
}

This clinical practice guideline was approved by Korean Knee Society on February 28, 2012. It is based on a systematic review of published studies on the management of postoperative pain after total knee arthroplasty and was developed to include the overall pain management modalities. The purpose of the guideline is to help improve treatment based on current best evidence. Eleven recommendations have been developed based on a systematic review of research evidence and the consensus opinions of a multidisciplinary working group of experts. These recommendations will be revised regularly following systematic review of new research evidence as this becomes available.

Key words: Postoperative pain management, Total knee arthroplasty, Guidelines.

\section{Introduction}

Despite the increasing interest in postoperative pain management and development of pain control modalities, more than half of the patients who undergo surgery experience inappropriate level of postoperative pain ${ }^{1-4)}$. In particular, pain after orthopedic surgery has been considered especially difficult to manage ${ }^{4-8)}$. Approximately half of total knee arthroplasty (TKA) patients present with extreme pain immediately after surgery ${ }^{1,2,9-11)}$.

Therefore, "immediate postoperative pain" is top on the list of concerns for TKA candidates ${ }^{12)}$, which often results in a delay or cancellation of the surgical intervention ${ }^{13)}$.

Severe postoperative pain after TKA can not only be a patient

Received April 15, 2012; Revised (1st) June 4, 2012; (2nd) June 30, 2012; Accepted July 6, 2012.

Correspondence to: Korean Knee Society.

Department of Orthopaedic Surgery, Seoul St. Mary's Hospital, The

Catholic University of Korea, 222 Banpo-daero, Seocho-gu, Seoul 137-

701 , Korea.

Tel: +82-2-2258-2838, Fax: +82-2-535-9834

Email: kks@koreaknee.or.kr

This is an Open Access article distributed under the terms of the Creative Commons Attribution Non-Commercial License (http://creativecommons.org/licenses/by-nc/3.0/) which permits unrestricted non-commercial use, distribution, and reproduction in any medium, provided the original work is properly cited. suffering but also negatively affect postoperative recovery. Extensive tissue damage in major operations, such as TKA, cause immediate changes in the endocrine system and central, peripheral, and sympathetic nervous systems, and stimulate catabolic hormone release including cortisol, glucagon, growth hormone, and catecholamine, resulting in compromised immunity, increased oxygen demand, and higher strain on the cardiovascular system ${ }^{11)}$. If severe postoperative pain is managed inadequately under these circumstances, the surgery-induced responses can be exacerbated, posing a serious danger to patients. Specifically, severe postoperative pain has been associated with serious complications including ischemic cardiac events and myocardiac insufficiency that result from increased stress on the cardiovascular system ${ }^{14)}$. In addition, immobilization caused by pain may increase the risk of decreased pulmonary function ${ }^{15)}$, gastrointestinal complications, such as ileus ${ }^{16)}$, and thrombus formation that are related to surgical stress. An increase in stress hormone and sleep disorder due to severe pain can worsen the already decreased immunity, which leads to higher risk of infection. In particular, this may affect the mental status of elderly patients, causing delirium or anxiety disorder ${ }^{8-11,17)}$. Uncontrolled severe immediate postoperative pain can develop into chronic pain due to the sensitization of the nerve system ${ }^{17,18)}$. Accordingly, early rehabilitation and recovery can be delayed, resulting in longer hospitalization, higher medical costs, and more burden on the health care provider ${ }^{1,2,8-11,14,15,19,20)}$. Pain after TKA is a particularly serious problem, considering the substantially increasing TKA use and the aging population. 
Therefore, proper management of pain after TKA is not just for the humane purpose of freeing patients from suffering. Rather, it is essential for successful TKA outcome in terms of improving patient satisfaction and quality of life and prevention of complications. The most important concept of current pain management following TKA is the preemptive use of multimodal approach. "Preemptive" refers to initiate pain management before surgical stimuli. In addition, "multimodal approach" means more than 2 drugs or modalities with different mechanisms or sites for synergistic effects. These two concepts have also been known to be remarkably effective for reducing the opioid consumption that has been associated with high complication rates.

\section{Postoperative Pain Management Guidelines for TKA}

The followings are the recommended modalities for the management of postoperative pain after TKA.

1) Patient education

2) Administration of preemptive analgesics

3) Neuraxial analgesia: epidural analgesia

4) Peripheral nerve block: femoral nerve block

5) Periarticular injection

6) Patient-controlled analgesia (PCA)

7) Oral analgesics

\section{Pain Management Methods}

We assigned a grade of recommendation of A, B, C, or I to each pain management method based on the review of the literature.

A (Recommended): Good evidence (Level I Studies [high quality randomized trial or systematic review of Level I studies] with consistent findings) for or against recommending intervention.

B (Effective): Fair evidence (Level II or III Studies [prospective or retrospective comparative study, case control study, or systematic review of level II or III study] with consistent findings) for or against recommending intervention.

C (Worth consideration): Poor quality evidence (Level IV or V Studies [case series or expert opinion]) for or against recommending intervention.

I (Inconclusive): Insufficient or conflicting evidence not allowing a recommendation for or against intervention.

\section{Basic Concepts}

1) Recommendation 1.1): Preemptive pain management

It is recommended to preemptively perform drug administration or other modalities for postoperative pain management prior to surgical incision.

Level of evidence: I, II

Grade of recommendation: A

Rationale for recommendation 1.1)

Preemptive use of pain control drugs (opioids ${ }^{21,22)}$, nonsteroidal anti-inflammatory drugs [NSAIDs], cyclo-oxygenase [COX]-2 inhibitors ${ }^{23,24)}$, and pregablin ${ }^{25-28}$ ) or pain management procedures (regional anesthesia ${ }^{29,30)}$ and peripheral nerve block ${ }^{31)}$ ) can be effective in reducing central \& peripheral sensitization and postoperative pain level, which results in decreased consumption of the analgesic agents after surgery ${ }^{8-10,19,32)}$. Preemptive pain management drugs should be orally administered with water or injected approximately 1 hour before surgery.

2) Recommendation 1.2): Multimodal pain management

It is recommended to use more than two agents or modalities with different mechanisms that act at different sites for multimodal pain management.

Level of evidence: I, II

Grade of recommendation: A

Rationale for recommendation 1.2)

A combined use of drugs or procedures that have different mechanisms of action can be more effective in improving pain and reducing the consumption of each agent. In particular, the opioid sparing effect would result in less complications ${ }^{8-10,19,23,33,34)}$.

\section{Preoperative Period}

1) Recommendation 2.1): Preoperative patient education

Preoperative education should be provided for patients and their family members before TKA. The content should include the overall surgical procedure and rehabilitation protocol, expected benefits of the procedure, postoperative pain level and pattern, and pain management methods. The effectiveness of the education can be improved through personal interviews or presentation sessions, or with use of educational media such as videos.

Level of Evidence: I, V

Grade of Recommendation: C

Rationale for Recommendation 2.1)

Preoperative education can be helpful in easing patient's fears about the procedure and providing a realistic picture of the possible outcomes, which would increase patient satisfaction and 
shorten hospitalization and rehabilitation period ${ }^{9,35-37)}$.

\section{2) Recommendation 2.2): Preemptive use of opioids}

Oral administration of opioids before surgery is effective for postoperative pain management.

Level of Evidence: I, II, III

Grade of Recommendation: B

Rationale for Recommendation 2.2)

Preoperative oral administration of opioids can be helpful for managing postoperative pain and reducing the use of opioid, but its influence on the occurrence of opiate side effects has not been established ${ }^{21}$. In a randomized study by Cheville et al. ${ }^{22}$, preemptive use of opioids in patients with TKA prior to rehabilitation improved pain control, accelerated functional recovery, and reduced the number of rehabilitation sessions. Although slow-release oxycodone has been the most commonly used narcotic for preemptive pain control, there is an increasing trend to exclude opioids from preemptive pain management protocol due to the risk of complications such as nausea and vomiting.

3) Recommendation 2.3): Preemptive use of COX-2 inhibitors

Preoperative oral administration of COX-2 inhibitors is recommended.

Level of Evidence: I

Grade of Recommendation: A

Rationale for Recommendation 2.3)

Preoperative oral administration of a COX-2 inhibitor can facilitate pain relief, reduce the need for opioids and related complications, and improve patient satisfaction. Furthermore, the efficacy and safety of COX-2 inhibitors for postoperative pain management have been well established ${ }^{11,23,35,38)}$. Nonselective NSAIDs that are expected to produce similar pain relieving effects enhances the risk of hemorrhage and upper gastrointestinal side effects. Accordingly, COX-2 inhibitors are recommended for preemptive pain management and celecoxib is the only available COX-2 inhibitor in Korea.

4) Recommendation 2.4) Preemptive use of gabapentin or pregabalin

The efficacy of preoperative oral administration of gabapentin or pregabalin has yet to be established.

Level of Evidence: I, V

Grade of Recommendation: I

Rationale for Recommendation 2.4)

Preoperative oral administration of gabapentin or pregabalin reduces postoperative pain and opioid consumption, and provides synergistic effects when used in combination with a COX-2 inhibitor after obstetric and gynecologic operations or spinal fusion ${ }^{25-28)}$. Although it appears to produce similar results in TKA, its efficacy should be determined in further studies.

\section{Intraoperative Period}

1) Recommendation 3.1): Use of regional anesthesia

Regional anesthesia either spinal or epidural is recommend over general anesthesia in the absence of specific contraindications such as coagulopathy.

Level of Evidence: I

Grade of Recommendation: A

Rationale for Recommendation 3.1)

Regional anesthesia lowers systolic pressure, reducing intraoperative hemorrhage, frequency of nausea and vomiting after surgery, and pulmonary and cardiovascular complications. It provides excellent pain relief and improves patient satisfaction $^{8-10,39-42)}$. Furthermore, epidural anesthesia allows for continuous infusion of pain medications via a catheter. However, care should be taken to interrupt deep venous thrombosis prophylaxis until 12 hours after epidural catheter removal due the risk of epidural hematoma and paraplegia following hemorrhage.

\section{2) Recommendation 3.2): Use of peripheral nerve block}

A peripheral nerve block such as femoral nerve block and sciatic nerve block is an effective adjuvant for pain management.

Level of Evidence: I, II, III

Grade of Recommendation: B

Rationale for Recommendation 3.2)

A peripheral nerve block can be performed with a singleinjection or continuous infusion via a catheter. Femoral nerve blocks are as effective as epidural anesthesia in pain relief ${ }^{33,43,44)}$ and single peripheral nerve block is advantageous for avoiding side effects associated with epidural analgesia, improving rehabilitation, and reducing hospital stay ${ }^{45-47)}$. These benefits are enhanced when it is used in conjunction with epidural analgesia ${ }^{48}$. However, caution has been advised with the use of continuous femoral nerve block because it has been associated with quadriceps femoris weakness, increased risk of falling after TKA, and compromised proprioception such as femoral neuritis ${ }^{49-52)}$.

3) Recommendation 3.3): Use of periarticular multimodal drug injection

Intraoperative periarticular multimodal drug injection using 
opioids and long-acting local anesthetic agents is effective for postoperative pain management.

Level of Evidence: I, II, III

Grade of Recommendation: B

Rationale for Recommendation 3.3)

Periarticular multimodal drug injection significantly reduces pain without any complications, such as infection ${ }^{9,20,53-55)}$ and produces additional pain relieving effects when incorporated into multimodal pain control protocols ${ }^{56-59)}$. However, the proper dosage and composition of injection cocktail and injection techniques have not been established and there is disagreement over its influence on reduced opioid consumption. Its efficacy is limited in time and patients should be informed on the occurrence of rebound pain after half-life of the treatment agents. The most commonly used drugs for periarticular injections include local anesthetics, such as bupivacaine and ropivacaine, morphine, ketololac, clonidine, and steroids. Epinephrine is often combined to prolong the effect and antibiotics, such as cefuroxime, to reduce the risk of infection. Steroids are advantageous for lengthening the duration of action of the periarticular injection, but rarely used in patients with high infection risks, such as diabetes or advanced age.

\section{Postoperative Period}

1) Recommendation 4.1): Use of Intravenous patient-controlled analgesia (IV-PCA)

IV-PCA is useful for postoperative pain management.

Level of Evidence: I, II, III

Grade of Recommendation: B

Rationale for Recommendation 4.1)

IV-PCA is the most common postoperative pain management modality that offers excellent analgesia with reduced rescue injection and analgesic drugs and improves patient satisfac$\operatorname{tion}^{60,611}$. However, inappropriate selection of equipment or analgesics may result in detrimental effects. In addition, IV-PCA should be used with extreme care in patients with advanced age due to the risk of opioid-related side effects including nausea and vomiting, respiratory or urinary failure, constipation, and pruritus $^{8,62)}$.

2) Recommendation 4.2): Use of multimodal oral analgesics after TKA

Multimodal oral pain regimens are recommended for postoperative pain management.

Level of Evidence: I

Grade of Recommendation: A
Rationale for Recommendation 4.2)

It is recommended to use multimodal oral pain regimens when oral administration becomes possible after surgery. The combined use of analgesics with different mechanisms of action produces synergistic effects such as maximum pain relief and reduced opioid consumption, which results in fewer complications and higher patient satisfaction ${ }^{8-10,19,63)}$. The commonly administered analgesics for pain after TKA include acetaminophen, COX-2 inhibitors, tramadol, and oxycontin. In contrast to the preemptive pain management modalities, postoperative methods employ short-acting opioids at frequent intervals for rapid pain relief and prompt management of complications.

\section{Conclusions}

Preemptive use of multimodal pain management approaches is currently recommended for postoperative pain control in TKA. Among a variety of pain management modalities that are available, a combined use of some modalities which were based on the assessment of advantages and disadvantages of each method, surgeon's techniques, and its own institution condition, would provide better surgical outcomes in terms of pain relief, systemic complication rate, early rehabilitation, patient satisfaction, and quality of life.

\section{References}

1. Filos KS, Lehmann KA. Current concepts and practice in postoperative pain management: need for a change? Eur Surg Res. 1999;31:97-107.

2. Follin SL, Charland SL. Acute pain management: operative or medical procedures and trauma. Ann Pharmacother. 1997;31:1068-76.

3. Sriwatanakul K, Weis OF, Alloza JL, Kelvie W, Weintraub M, Lasagna L. Analysis of narcotic analgesic usage in the treatment of postoperative pain. JAMA. 1983;250:926-9.

4. Warfield CA, Kahn CH. Acute pain management. Programs in U.S. hospitals and experiences and attitudes among U.S. adults. Anesthesiology. 1995;83:1090-4.

5. Apfelbaum JL, Chen C, Mehta SS, Gan TJ. Postoperative pain experience: results from a national survey suggest postoperative pain continues to be undermanaged. Anesth Analg. 2003;97:534-40, table of contents.

6. Chung F, Ritchie E, Su J. Postoperative pain in ambulatory surgery. Anesth Analg. 1997;85:808-16.

7. Rawal N, Hylander J, Nydahl PA, Olofsson I, Gupta A. 
Survey of postoperative analgesia following ambulatory surgery. Acta Anaesthesiol Scand. 1997;41:1017-22.

8. Parvizi J, Porat M, Gandhi K, Viscusi ER, Rothman RH. Postoperative pain management techniques in hip and knee arthroplasty. Instr Course Lect. 2009;58:769-79.

9. Maheshwari AV, Blum YC, Shekhar L, Ranawat AS, Ranawat CS. Multimodal pain management after total hip and knee arthroplasty at the Ranawat Orthopaedic Center. Clin Orthop Relat Res. 2009;467:1418-23.

10. Parvataneni HK, Ranawat AS, Ranawat CS. The use of local periarticular injections in the management of postoperative pain after total hip and knee replacement: a multimodal approach. Instr Course Lect. 2007;56:125-31.

11. Sinatra RS, Torres J, Bustos AM. Pain management after major orthopaedic surgery: current strategies and new concepts. J Am Acad Orthop Surg. 2002;10:117-29.

12. Park KK, Shin KS, Chang CB, Kim SJ, Kim TK. Functional disabilities and issues of concern in female Asian patients before TKA. Clin Orthop Relat Res. 2007;461:143-52.

13. Trousdale RT, McGrory BJ, Berry DJ, Becker MW, Harmsen WS. Patients' concerns prior to undergoing total hip and total knee arthroplasty. Mayo Clin Proc. 1999;74:978-82.

14. Mangano DT, Wong MG, London MJ, Tubau JF, Rapp JA. Perioperative myocardial ischemia in patients undergoing noncardiac surgery--II: Incidence and severity during the 1st week after surgery. The Study of Perioperative Ischemia (SPI) Research Group. J Am Coll Cardiol. 1991;17:851-7.

15. Wisner DH. A stepwise logistic regression analysis of factors affecting morbidity and mortality after thoracic trauma: effect of epidural analgesia. J Trauma. 1990;30:799-804.

16. Wattwil M. Postoperative pain relief and gastrointestinal motility. Acta Chir Scand Suppl. 1989;550:140-5.

17. Carr DB, Goudas LC. Acute pain. Lancet. 1999;353:2051-8.

18. Samad TA, Moore KA, Sapirstein A, Billet S, Allchorne A, Poole S, Bonventre JV, Woolf CJ. Interleukin-1beta-mediated induction of Cox-2 in the CNS contributes to inflammatory pain hypersensitivity. Nature. 2001;410:471-5.

19. Krych AJ, Horlocker TT, Hebl JR, Pagnano MW. Contemporary pain management strategies for minimally invasive total knee arthroplasty. Instr Course Lect. 2010;59:99-109.

20. Parvataneni HK, Shah VP, Howard H, Cole N, Ranawat AS, Ranawat CS. Controlling pain after total hip and knee arthroplasty using a multimodal protocol with local periarticular injections: a prospective randomized study. J Arthroplasty. 2007;22:33-8.

21. Bromley L. Pre-emptive analgesia and protective premedica- tion. What is the difference? Biomed Pharmacother. 2006;60: 336-40.

22. Cheville A, Chen A, Oster G, McGarry L, Narcessian E. A randomized trial of controlled-release oxycodone during inpatient rehabilitation following unilateral total knee arthroplasty. J Bone Joint Surg Am. 2001;83:572-6.

23. Buvanendran A, Kroin JS, Tuman KJ, Lubenow TR, Elmofty D, Moric M, Rosenberg AG. Effects of perioperative administration of a selective cyclooxygenase 2 inhibitor on pain management and recovery of function after knee replacement: a randomized controlled trial. JAMA. 2003;290:2411-8.

24. Reuben SS, Bhopatkar S, Maciolek H, Joshi W, Sklar J. The preemptive analgesic effect of rofecoxib after ambulatory arthroscopic knee surgery. Anesth Analg. 2002;94:55-9.

25. Reuben SS, Buvanendran A, Kroin JS, Raghunathan K. The analgesic efficacy of celecoxib, pregabalin, and their combination for spinal fusion surgery. Anesth Analg. 2006;103:1271-7.

26. Turan A, Karamanlioglu B, Memis D, Hamamcioglu MK, Tukenmez B, Pamukcu Z, Kurt I. Analgesic effects of gabapentin after spinal surgery. Anesthesiology. 2004;100:935-8.

27. Turan A, Karamanlioglu B, Memis D, Usar P, Pamukcu $Z$, Ture $M$. The analgesic effects of gabapentin after total abdominal hysterectomy. Anesth Analg. 2004;98:1370-3.

28. Turan A, White PF, Karamanlioglu B, Memis D, Tasdogan M, Pamukcu Z, Yavuz E. Gabapentin: an alternative to the cyclooxygenase-2 inhibitors for perioperative pain management. Anesth Analg. 2006;102:175-81.

29. Klasen J, Haas M, Graf S, Harbach H, Quinzio L, Jurgensen I, Hempelmann G. Impact on postoperative pain of longlasting pre-emptive epidural analgesia before total hip replacement: a prospective, randomised, double-blind study. Anaesthesia. 2005;60:118-23.

30. Ong CK, Lirk P, Seymour RA, Jenkins BJ. The efficacy of preemptive analgesia for acute postoperative pain management: a meta-analysis. Anesth Analg. 2005;100:757-73.

31. Ringrose NH, Cross MJ. Femoral nerve block in knee joint surgery. Am J Sports Med. 1984;12:398-402.

32. Mallory TH, Lombardi AV Jr, Fada RA, Dodds KL, Adams JB. Pain management for joint arthroplasty: preemptive analgesia. J Arthroplasty. 2002;17:129-33.

33. Hebl JR, Kopp SL, Ali MH, Horlocker TT, Dilger JA, Lennon RL, Williams BA, Hanssen AD, Pagnano MW. A comprehensive anesthesia protocol that emphasizes 
peripheral nerve blockade for total knee and total hip arthroplasty. J Bone Joint Surg Am. 2005;87 Suppl 2:63-70.

34. White PF. The changing role of non-opioid analgesic techniques in the management of postoperative pain. Anesth Analg. 2005;101:S5-22.

35. Huang YM, Wang CM, Wang CT, Lin WP, Horng LC, Jiang CC. Perioperative celecoxib administration for pain management after total knee arthroplasty-a randomized, controlled study. BMC Musculoskelet Disord. 2008;9:77.

36. Maheshwari AV, Boutary M, Yun AG, Sirianni LE, Dorr LD. Multimodal analgesia without routine parenteral narcotics for total hip arthroplasty. Clin Orthop Relat Res. 2006;453:231-8.

37. Sinatra R. Role of COX-2 inhibitors in the evolution of acute pain management. J Pain Symptom Manage. 2002;24:S1827.

38. Reuben SS, Buvenandran A, Katz B, Kroin JS. A prospective randomized trial on the role of perioperative celecoxib administration for total knee arthroplasty: improving clinical outcomes. Anesth Analg. 2008;106:1258-64.

39. Christopherson R, Beattie C, Frank SM, Norris EJ, Meinert CL, Gottlieb SO, Yates H, Rock P, Parker SD, Perler BA, Willams GM; The Perioperative Ischemia Randomized Anesthesia Trial Study Group. Perioperative morbidity in patients randomized to epidural or general anesthesia for lower extremity vascular surgery. Perioperative Ischemia Randomized Anesthesia Trial Study Group. Anesthesiology. 1993;79:422-34.

40. Thorburn J, Louden JR, Vallance R. Spinal and general anaesthesia in total hip replacement: frequency of deep vein thrombosis. Br J Anaesth. 1980;52:1117-21.

41. Sharrock NE, Haas SB, Hargett MJ, Urquhart B, Insall JN, Scuderi G. Effects of epidural anesthesia on the incidence of deep-vein thrombosis after total knee arthroplasty. J Bone Joint Surg Am. 1991;73:502-6.

42. Indelli PF, Grant SA, Nielsen K, Vail TP. Regional anesthesia in hip surgery. Clin Orthop Relat Res. 2005;441:250-5.

43. Capdevila X, Barthelet Y, Biboulet P, Ryckwaert Y, Rubenovitch J, d'Athis F. Effects of perioperative analgesic technique on the surgical outcome and duration of rehabilitation after major knee surgery. Anesthesiology. 1999;91:8-15.

44. Horlocker TT, Kopp SL, Pagnano MW, Hebl JR. Analgesia for total hip and knee arthroplasty: a multimodal pathway featuring peripheral nerve block. J Am Acad Orthop Surg. 2006;14:126-35.
45. Chelly JE, Greger J, Gebhard R, Coupe K, Clyburn TA, Buckle R, Criswell A. Continuous femoral blocks improve recovery and outcome of patients undergoing total knee arthroplasty. J Arthroplasty. 2001;16:436-45.

46. Singelyn FJ, Deyaert M, Joris D, Pendeville E, Gouverneur JM. Effects of intravenous patient-controlled analgesia with morphine, continuous epidural analgesia, and continuous three-in-one block on postoperative pain and knee rehabilitation after unilateral total knee arthroplasty. Anesth Analg. 1998;87:88-92.

47. Singelyn FJ, Ferrant T, Malisse MF, Joris D. Effects of intravenous patient-controlled analgesia with morphine, continuous epidural analgesia, and continuous femoral nerve sheath block on rehabilitation after unilateral total-hip arthroplasty. Reg Anesth Pain Med. 2005;30:452-7.

48. YaDeau JT, Cahill JB, Zawadsky MW, Sharrock NE, Bottner F, Morelli CM, Kahn RL, Sculco TP. The effects of femoral nerve blockade in conjunction with epidural analgesia after total knee arthroplasty. Anesth Analg. 2005;101:891-5.

49. Sharma S, Iorio R, Specht LM, Davies-Lepie S, Healy WL. Complications of femoral nerve block for total knee arthroplasty. Clin Orthop Relat Res. 2010;468:135-40.

50. Kandasami M, Kinninmonth AW, Sarungi M, Baines J, Scott NB. Femoral nerve block for total knee replacement-a word of caution. Knee. 2009;16:98-100.

51. Lynch J. Prolonged motor weakness after femoral nerve block with bupivacaine 0.5\%. Anaesthesia. 1990;45:421.

52. McNicol LR. Palsy after femoral nerve block. Anaesthesia. 1988;43:509.

53. Busch CA, Shore BJ, Bhandari R, Ganapathy S, MacDonald SJ, Bourne RB, Rorabeck CH, McCalden RW. Efficacy of periarticular multimodal drug injection in total knee arthroplasty. A randomized trial. J Bone Joint Surg Am. 2006;88:959-63.

54. Vendittoli PA, Makinen P, Drolet P, Lavigne M, Fallaha M, Guertin MC, Varin F. A multimodal analgesia protocol for total knee arthroplasty. A randomized, controlled study. J Bone Joint Surg Am. 2006;88:282-9.

55. Chelly JE, Gebhard R, Greger J, Al Samsam T. Regional anesthesia for outpatient orthopedic surgery. Minerva Anestesiol. 2001;67:227-32.

56. Koh IJ, Kang YG, Chang CB, Do SH, Seong SC, Kim TK. Does periarticular injection have additional pain relieving effects during contemporary multimodal pain control protocols for TKA?: A randomised, controlled study. Knee. 2012;19:253-9. 
57. Koh IJ, Kang YG, Chang CB, Kwon SK, Seo ES, Seong SC, Kim TK. Additional pain relieving effect of intraoperative periarticular injections after simultaneous bilateral TKA: a randomized, controlled study. Knee Surg Sports Traumatol Arthrosc. 2010;18:916-22.

58. Andersen LO, Husted H, Kristensen BB, Otte KS, GaarnLarsen L, Kehlet H. Analgesic efficacy of subcutaneous local anaesthetic wound infiltration in bilateral knee arthroplasty: a randomised, placebo-controlled, double-blind trial. Acta Anaesthesiol Scand. 2010;54:543-8.

59. Mullaji A, Kanna R, Shetty GM, Chavda V, Singh DP. Efficacy of periarticular injection of bupivacaine, fentanyl, and methylprednisolone in total knee arthroplasty:a prospective, randomized trial. J Arthroplasty. 2010;25:851-7.

60. Grass JA. Patient-controlled analgesia. Anesth Analg. 2005;101:S44-61.

61. Macintyre PE. Intravenous patient-controlled analgesia: one size does not fit all. Anesthesiol Clin North America. 2005;23:109-23.

62. Crawford CH 3rd, Malkani AL. Patient-controlled analgesia for total joint arthroplasty. Instr Course Lect. 2007;56:115-9.

63. Sinatra RS, Jahr JS, Reynolds LW, Viscusi ER, Groudine SB, Payen-Champenois C. Efficacy and safety of single and repeated administration of 1 gram intravenous acetaminophen injection (paracetamol) for pain management after major orthopedic surgery. Anesthesiology. 2005;102:822-31. 